\title{
DE LA DESESPERACIÓN DE SÖREN KIERKEGAARD, A LA ANGUSTIA DE MARTIN HEIDEGGER
}

\author{
Al Dr. Alberto Wagner de Reyna (1915-2006) \\ Maestro de nuestro tiempo \\ "in memoriam"
}

Miryam Falla Guirao*

\section{RESUMEN:}

El postmodernismo ha conducido al hombre a plantear la pregunta por el sentido de su existencia y su lugar en el mundo. El exceso de bienestar y progreso no ha logrado satisfacer todas las aspiraciones "humanas": Antes bien, lo ha llevado a una falta de creatividad, disfuncionalidad en las relaciones interpersonales, depresión y angustia existencial. La angustia ante la muerte inexorable que no se sabe cuándo llega, conduce al hombre a un sistema de aniquilamiento interior y desesperación. Por eso dice, "o soy el César o nada". En tanto, que Martín Heidegger reconoce la "angustia" en que sucumbe el "ser" enfrentado a la muerte que es un "misterio". Así, el sentido de la existencia debe ser enfrentada sin que con ello se puedan evitar los más profundos temores como la angustia, desesperación o aburrimiento.

PALABRAS CLAVE: Posmodernidad. Nihilismo, Angustia. Desesperación. Aburrimiento. Miedo.

\section{FROM THE CONCEPT "DESPERATION" IN SOREN KIERKEGAARD TO “ANXIETY” ACCORDING TO MARTIN HEIDEGGER}

\begin{abstract}
Postmodernism has conducted to the man to questioning his existence and place notion in the world. The excess of welfare and progress couldn't fulfill with all the "human" aspirations. It is related to a lack of creativity, dysfunction on interpersonal relationships, depression and existential anxiety. The anxiety in front of the inescapable death which is not sure when it will happen, leads the man to a system of internal annihilation and desperation. That is why he mentions: "either Caesar or nothing". Therefore, Martín Heidegger recognizes the "anxiety" in which succumbs the "being" facing death that is a "mystery". The sense of the existence must be confronted without avoiding the fact of the deepest fears as anxiety, desperation or boredom.
\end{abstract}

KEY WORDS: Postmodernity, Nihilism, Anxiety, Desperation, Boredom, Fear.

*Licenciada en Filosofía por la Pontificia Universidad Católica del Perú, y Doctora en Filosofía por la Pontificia Universidad Católica Argentina. Actualmente es profesora del Dpto. de Filosofía y Teología de la UNIFE, y en la escuela de posgrado de la misma Casa de Estudios. Ha sido becaria del Consejo Nacional de Investigaciones Científicas y Técnicas de la Rep. Argentina (CONICET). Especialista en Bioética, conferencista en Universidades, Colegios Profesionales e Instituciones de Salud. 
Los desafíos de la sociedad posmoderna, nos enfrenta al diálogo reflexivo con el existencialismo, sobre todo en la coyuntura nihilista a la que hemos llegado, como producto de la crisis moral engendrada por una ideología dominada por el cientificismo, la tecnocracia y la industria.

El exceso de bienestar y progreso al que aspira el ser humano, alcanzado sobre todo por las culturas occidentales, ha traído como consecuencia insatisfacción, falta de creatividad, disfuncionalidad en las relaciones interpersonales, y depresiones endógenas; siendo considerada esta última -según la OMS- como la segunda enfermedad de mayor incidencia en el mundo de aquí al año 2020, después de las enfermedades cardiovasculares; a la que se le ha denominado "La enfermedad de la tristeza", siendo catalogada como la gran epidemia posmoderna del siglo XXI.

Angustiay desesperación, son dos conceptos que invaden la atmósfera social de nuestro siglo. Desde el análisis psicológico, al fenomenológico y existencialista, arrojan luces para comprender la coyuntura actual, en la cual el espacio filosófico y religioso, es llamado a responder a las grandes interrogantes del hombre de hoy.

En su célebre Tratado de la desesperación, ${ }^{31}$ el filósofo danés Sören Kierkegaard, pone énfasis en lo que verdaderamente debe entenderse por desesperación, llegando a identificar esta experiencia psicológica como la "enfermedad mortal".

En su común significado, enfermedad mortal, quiere decir, aquel mal del cuerpo que conduce inexorablemente a la muerte. Cuando decimos que una enfermedad es mortal, aludimos a un estado patológico cuya consecuencia inmediata es la muerte, a corto o mediano plazo, descartando todo tipo de tratamiento de reversibilidad.

Lo generalmente acontecible es que la presencia de una enfermedad mortal, produzca un estado de desesperación en el individuo, que no pocas veces ha culminado en un auto aniquilamiento del propio sujeto. ${ }^{32}$ Pero en este caso, sucede a la inversa, no es la desesperación por la enfermedad mortal, sino que la misma desesperación es para Kierkegaard, la gran enfermedad mortal. Nuestro filósofo la define así, porque el hombre desespera de "no poder morir"." Este "no poder morir", tiene su asidero en una vida totalmente vacía de esperanza. Cuando el hombre se reconoce como finito, que más allá de su existencia terrena no hay infinitud, entonces desespera de su propia condición, intentando fallidamente autoaniquilarse como sujeto.

Pero este auto aniquilamiento no ocurre en la forma de acabar con su propia vida, sino en huir de sí mismo como quien huye del sin sentido, para refugiarse en caminos propiamente

\footnotetext{
${ }^{31}$ Kierkegaard, Sören; Tratado de la desesperación, Barcelona, Edicomunicación S.A, Col. Fontana, 1994

${ }^{32}$ Nos referimos al suicidio que acontece como consecuencia de la incapacidad de sobrellevar una enfermedad mortal, o a la depresión que produce la misma.

33 En Kierkegaard el sentido de muerte hay que interpretarlo desde la fe, es decir, como un paso a la vida. Si el hombre desespera de no poder morir, en realidad, está desesperando de su finitud.
} 
mundanos. Por eso dice sin miramiento: ... "o soy el César o nada" ${ }^{34}$.. Si el individuo no consigue ser el César, entonces vuelve a desesperar porque tiene que volver hacia sí mismo, hacia su propia mismidad desprovista del disfraz mundano que podía representar ser el César, y que lo devuelve al sujeto que busca morir pero no puede, ya que para Kierkegaard "morir" es "renacer" a la eternidad.

Este sujeto no puede morir y mucho menos renacer, porque se siente atrapado por la finitud del mundo y por un vacío existencial que solo puede superar por la fe. Volveremos a este punto luego.

Cuando Martin Heidegger en su lección inaugural ¿Qué es metafísica?, pone énfasis en el temple de la angustia como el estado de ánimo que hace patente la nada, en la cual se sostiene el ente y por lo tanto, el ser en general, describe un estado anímico similar a la desesperación kierkegaardiana que auto descubre una existencia vacía.

Pero a diferencia de la angustia en Heidegger, la desesperación kierkegaardiana es un concepto que discurre por senderos psicológicos, es decir, que el que desespera, desespera siempre de "algo". En este caso, desespera de no poder desprenderse de su yo. El que verdaderamente desespera, es aquél que debe dar el salto al pozo sin fondo y enfrentarse al sin sentido; o correr hacia los brazos de la fe que lo alberga en una cálida esperanza. La esperanza de esta desesperanza es el Cristo Crucificado que lo redime de los pecados del mundo.

Quien desespera a la manera de Kierkegaard, sabe de qué está desesperando cuando sobreviene este sentimiento, por eso huye hacia el mundo y se refugia en la superficie de la vanidad o de una profundidad entendida sólo en niveles acomodaticios. Por eso dirá en el "Tratado de la desesperación", que aquél que toma conciencia de su verdadera esencia y destino, será representado por el individuo que asume la naturaleza de su yo de manera enmascarada.

El que se enmascara, será un sujeto que se reconoce como dependiente del Creador, por lo tanto, actuará de manera moralmente intachable, se regocijará en la Iglesia dándole gracias a Dios por su existencia y la de los suyos, gozará de un merecido prestigio, será un sujeto de buena voluntad consigo y con los demás, pero huirá siempre de su propio yo, acercándose a la vanidad del mundo de manera "correcta", sin que nadie tenga que decir de él.

Por eso insiste el filósofo danés, que para dar ese salto al vacío en el cual sentimos que Dios nos lanza una cuerda de salvación, es menester primeramente reconocerse como "pecador". Sólo reconociéndonos como pecadores y asumiendo la porción de culpa que nos corresponde, podemos mirar el mundo

\footnotetext{
${ }^{34}$ Cfr. Kierkegaard, S; o. cit

${ }^{35}$ Heidegger, Martin; ¿Qué es metafísica?

36 Kierkegaard, Sören; $o b$. cit
} 
con ojos iluminados, encontrándole un sentido que borra la desesperación propia del hombre.

La fórmula de Kierkegaard puede leerse de la siguiente manera: desesperamos porque sabemos que estamos en un mundo que se nos acaba; que no adquiere un sentido pleno que colme nuestra existencia, por eso huimos de nuestro propio yo, plagado de inseguridad e inercia y nos refugiamos en un mundo que nos distrae y nos hace asumir un papel específico dotado de configuración e identidad. Cuando todo esto se aleja, entonces sobreviene la desesperación, porque nos percatamos que detrás de esto no hay nada. Por lo tanto, no podemos morir adecuadamente.

La gran enfermedad mortal, se torna entonces en "paradójica", porque es la enfermedad humana que no le permite al hombre "morir". Recordemos que para Kierkegaard, se muere verdaderamente cuando se renace. La condición para renacer es asumirse como pecador y culpable y arrojarse a los brazos del Creador que todo lo perdona, habiendo ofrendado su vida por ello.

Kierkegaard es eminentemente un pensador religioso, donde su manera de ver el mundo y el puesto que le corresponde al hombre en el cosmos, se convierten en toda una concepción filosófica. Sus conceptos fundamentales no lo hacen un teólogo necesariamente, porque sus ideas no giran en torno de un Dios; o de Dios y su relación con el hombre; sino que dan la vuelta a la inversa y parten de la condición humana para desnudarla en un vacío que sólo puede serllenado por la fe.

Martin Heidegger va a tomar los parámetros de Kierkegaard para elaborar su propia doctrina. Su punto de partida es también el hombre, al que define como un "ser-en-el-mundo". Esta expresión alude a un ser que se auto descubre en un mundo que constantemente lo interroga, para terminar interrogándose por él mismo; por eso dice al respecto del "dasein" (ser-ahî), que es el único ser "en cuyo ser le va su ser".

Cuando el ser-ahí (dasein) se descubre como un ser que se comprende como una modalidad del ente en particular, es decir, como un ente al que se le abre paso el ente y por lo tanto el ser del ente por medio del lenguaje, entonces es en ese preciso momento que se capta como "existencia". El término "existencia" alude al hombre mismo que se comprende como un ente en una peculiar modalidad de ser.

Esta modalidad de ser lo devela como aquél que puede nombrar todo aquello que sale a su paso, por ello Heidegger insiste en que sólo por medio del lenguaje es posible no sólo captar al ente en su ser, sino conocerlo y comprenderlo. El hombre al abrirse paso en el mundo, en medio de los entes, lo nombra (apophansis).

${ }^{37}$ Heidegger, Martin; El ser y el tiempo, México, Fondo de Cultura Económica, 2000

38 Esta expresión alude a la capacidad del hombre de comprenderse como un ente en medio de otros, cuya diferencia es el poder descubrirse como tal. 
El hombre habiéndose captado en el mundo, no sólo por la presencia de los otros entes sino por la capacidad de nombrarlo y reconocerlo a través del lenguaje, se descubre con otros entes semejantes a él con los cuales tiene que interactuar para sobrevivir. A este fenómeno Heidegger lo denominó "la cura" o "el cuidado". El hombre se devela a sí mismo en la cura, la que lo empuja inexorablemente a la impropiedad y al anonimato en el universo del Uno (das Mann)..$^{39}$

Sumergido en el Uno, el dasein (Ser-ahî) descubre la precariedad de su existencia, precariedad que lo devuelve a su propiedad, aunque sea solo un instante. Pero ¿cómo accede a develarse a sî mismo? Heidegger habla específicamente de dos temples de ánimo que hacen patente la "nada" como aquello que soporta al ente, que lo sostiene en medio de ella. Estos temples de ánimo son el aburrimiento y la angustia.

"Uno se aburre" (Es langweilt einen). Esta expresión indica que la causa del aburrimiento puede ser "todo o nada". Lo que Hiedegger indica, es que la causa del aburrimiento es generalmente algo indeterminado. Este aburrimiento hay que entenderlo existencialmente, porque es obvio que algo determinado puede llegar a aburrirnos; como quien dice:.....me aburre mi trabajo. Es posible que determinada labor lo aburra, pero si cambia de actividad, entonces este tipo de sensación, cesa.

$\mathrm{El}$ aburrimiento existencial es aquel en el que todo puede llegar a aburrir, como "lo que no nos llena" y produce ese estado anímico. Es así como llegamos a la nada como causa de aburrimiento, como aquél tiempo vacío carente de contenido. En este sentido, Heidegger habla de indeterminación, por eso, en ¿Qué es metafísica? indica que en el aburrimiento se nos revela "la omnitud del ente" o el "ente en su totalidad".

Es ahí, en la totalidad del ente que no nos revela sentido alguno, cómo éste comienza a escaparse, sobreviniendo tras él la nada que lo sostiene. Antes de experimentar esta nada sostenedora, es necesario haber alcanzado los estados de ánimo que la hacen posible, a saber, el aburrimiento y la alegría.

Así como en el aburrimiento captamos la totalidad del mundo, también en la alegría podemos captar con mayor atención "que las cosas, son", porque dicho sentimiento es el más propicio para llamar nuestra atención sobre las cosas; algo así como decir que la dicha permite que el ente venga hacia nosotros, mientras que en el aburrimiento se nos escapa. Por eso, el "uno se aburre", alude a un yo indeterminado que es arrasado como una ola gigantesca que consume lo que encuentra a su paso,

${ }^{39}$ El Uno (das Man) es para Heidegger, el impersonal. Por ej. "uno se cansa". Esta expresión remite directamente al que está en medio de los otros sin identificarse. Uno, puede ser cualquiera, por eso es la pérdida en el anonimato.

$40 \mathrm{GA}$, Gesamtasugabe. Ausgabe Letzter Hand, Vittorio Klostermann-Verlag, Frankfurt, cit por Safranski, Rüdiger; Un maestro de Alemania (Martín Heidegger y su tiempo), Barcelona, TusQuets, 1997.

${ }^{41}$ Heidegger, M; ¿Qué es metafísica?, ob. cit 
del todo hacia la nada.

Heidegger pone énfasis, a diferencia de Kierkegaard, que el sentimiento de angustia no tiene un objeto que la produzca; no se trata por lo tanto de una angustia psicológica, y mucho menos del miedo, porque el miedo es siempre miedo de algo, mientras que la angustia es angustia de "nada". ¿Cómo entender esto? ¿Si la angustia tiene siempre un motivo, por qué puede ser angustia de "nada?

El análisis existencial lo describe como un temple de ánimo en el que se nos revela la finitud, y tras ella, nada; es decir, cuando tras el aburrimiento el ente se nos escapa, sobreviene la nada como el soporte de todo lo que nos rodea. Este sentimiento es tan particular y revelador de la condición del ente finito, que cuando se nos pregunta qué nos angustia, nuestra inexorable respuesta es, nada.

Decimos "nada" porque no hay algo determinado que la produzca y porque nos cuesta traducir en palabras esa extraña sensación de la cual sobrevendrá la pregunta eminentemente metafísica: ¿por qué es en general el ente, y no más bien la nada?; o dicho de otro modo, ¿por qué somos cuando podríamos no haber sido? Este habernos descubierto como "moviéndonos en la nada" nos describe nuestra verdadera propiedad. Luego de dicha experiencia existencial, el dasein huye hacia el Uno para refugiarse en la impropiedad, precisamente porque le cuesta asumir su condición.

Kierkegaard se mueve en parámetros muy parecidos. En su análisis existencial, el filósofo danés indica que el hombre desespera cuando descubre su finitud como carente de muerte, entonces huye hacia el mundo y se pone el disfraz que lo hace olvidar de quién es realmente; ya sea el de César o el que se ajuste a su personalidad.

El fracaso en el intento, lo devolverá a su propio yo, a aquél del que ha venido huyendo, entonces se produce la desesperación que para Kierkegaard es un sentimiento eminentemente psicológico. El que desespera, desespera de algo, en este caso, de su propio yo, a saber, de la propia libertad nadando en las aguas de la finitud. A diferencia de Heidegger, que no propone modelos de comportamiento, Kierkegaard pone énfasis en que sólo el reconocerse como pecador en la culpa, puede redimir al hombre y hacerlo dar el salto a la fe. Sólo por Cristo y en Cristo, nuestra vida adquiere un significado que sólo se devela ante la humildad de quien reconoce la falta ante el sublime Creador que lo perdona y acoge en la eternidad.

Desespera el que no quiere asumirse como ser creado, culpable y pecador, y ver en la fe, el único refugio. Se angustia el que se descubre moviéndose en medio de la nada, sin que ello le de una respuesta concreta. ${ }^{43}$ Por eso, cuando el dasein es

\footnotetext{
${ }^{42}$ Recordemos que la muerte es para Kierkegaard, vida. Sólo renace el que muere. La enfermedad mortal, es la enfermedad que no le permitirá al hombre renacer nuevamente y otorgarle un sentido a la existencia; sentido que sólo puede verse en la vida ultraterrena.

${ }^{43} \mathrm{Si}$ bien Heidegger reconoce en sus últimas obras "al Dios venidero", su filosofía es básicamente una filosofía de lo "finito".
} 
interrogado acerca de qué es lo que lo angustia, su respuesta es: "nada", porque le cuesta representar a través del lenguaje el significado de esa sensación.

Esto no significa que no pueda hacerlo, sino que el mundo cotidiano en el que están absortos los demás, impide que los otros comprendan realmente lo que está experimentando. Quien está inmerso en el Uno (das Man), está sumergido en la impropiedad, y esto lo dificulta para entender cabalmente los alcances de quien ha llegado a descubrir conceptualmente la propiedad de la existencia, específicamente, de la existencia humana.

Desesperación y angustia son básicamente dos sentimientos muy parecidos, y ambos con un cariz psicológico preponderante. ${ }^{44}$ Mientras Kierkegaard reconoce este factor como específico para entender su pensamiento, Heidegger, lo niega, enfatizando que su modo de ver la angustia no implica un temple psicológico.

En Heidegger, la angustia es metafóricamente, el instrumento fenomenológico por medio del cual el hombre va a descubrir "lo que queda", luego de poner "entre paréntesis" la totalidad del ente, a saber, la nada, y él moviéndose en ella. Para Kierkegaard, sólo desespera el "que no tiene esperanza”, y precisamente el que desespera es aquél que huye al mundo porque no encuentra nada más fuera de él. La desesperación es para Kierkegaard, el salto que debe conducir al hombre a la esperanza por la fe. Sólo el gran salto hacia "lo infinito", puede curar la gran "enfermedad mortal".

Dos autores que apuntan hacia un mismo dilema; la finitud del ente y con ella, la finitud del hombre. En Kierkegaard, detrás del ente, el todo; en Heidegger, detrás del ente, la nada. A la pregunta ¿por qué es en general el ente y no más bien la nada? Kierkegaard respondería con la fe: por el amor de un Dios que nos ha creado y al que debemos volver por la salvación, primeramente reconociéndonos como culpables y pecadores, y como causantes de la finitud de un paraíso que fue creado para la eternidad. Heidegger deja la pregunta en suspenso, para que ella sea precisamente el medio que conduzca al dasein a descubrir su esencia propia, es decir, su autenticidad.

\footnotetext{
${ }^{44} \mathrm{El}$ angustiado es básicamente, un desesperado. La angustia, en una de sus modalidades, es una forma de desesperación.
} 


\section{Referencias}

- Heidegger, Martin. (2000). El ser y el tiempo. México: Fondo de Cultura Económica.

- Heidegger, Martin. (1983). ¿Qué es metafísica? Buenos Aires: Ed, siglo XX.

- Kierkegaard, Sören. (1994). Tratado de la desesperación. Barcelona: Edicomunicaciones, Col. Fontana.
- Safranski, Rüdiger. (1997). Un maestro de Alemania (Heidegger y su tiempo). Barcelona:TusQuets.

- Wagner De Reyna, Alberto. (1938). La ontología fundamental de Heidegger. Buenos Aires: Losada.

- Wagner De Reyna, Alberto. (1959). Hacia más allá de los linderos. Argentina: Universidad Nacional de Tucumán. 